BETH NÉSPOLI

é jornalista e escreve

sobre teatro no Caderno 2

do jornal 0 Estado de

S.Paulo.

Idéias Teatrais: o Século

$X I X$ no Brasil, de João

Roberto de Faria, São

Paulo, Perspectiva, 2001.

Outros tempos do

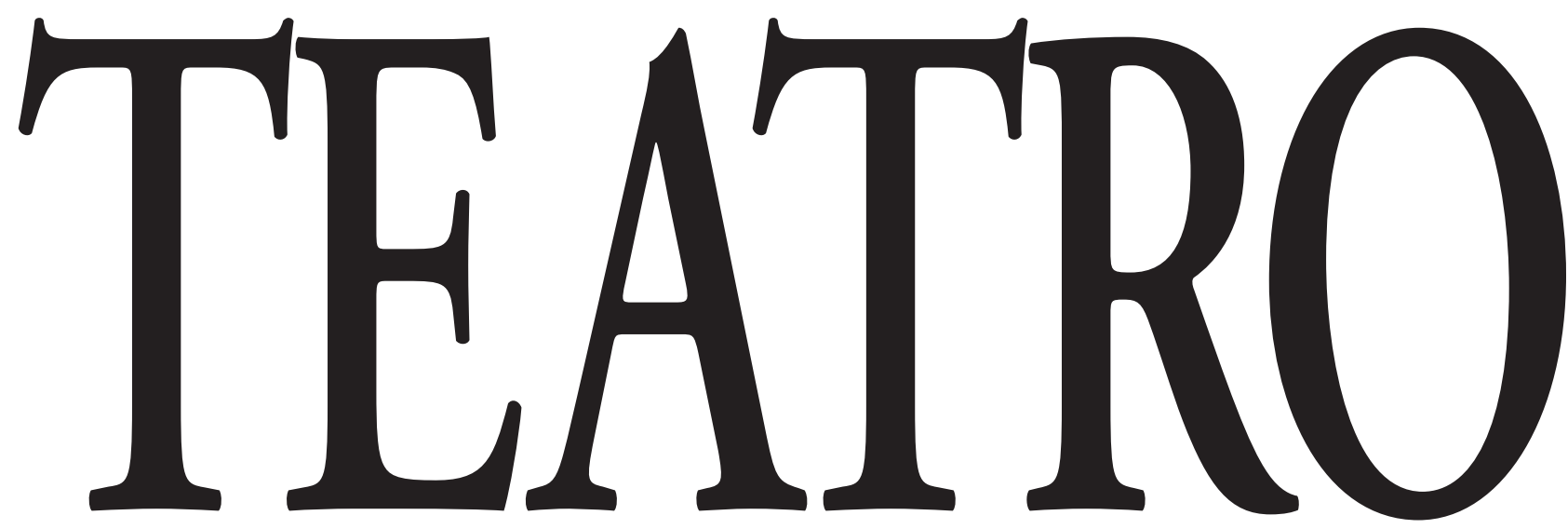


Os bons livros de crítica, a exemplo dos bons romances e das boas peças de teatro, têm sempre um certo enredo. Assim Decio de Almeida Prado inicia o prefácio do livro José de Alencar e o Teatro, de João Roberto de Faria. O crítico elogia o talento do autor que, segundo ele, revelava-se, nesse seu livro de estréia, "um excelente narrador" ao contar de forma clara, fluente, concisa e segura uma história - "como tantas outras do teatro brasileiro" - que vai dos primeiros triunfos aos últimos dissabores de um promissor dramaturgo.

Decio de Almeida Prado não teve a oportunidade de prefaciar o mais recente livro de João Roberto de Faria, lançado pela editora Perspectiva, Idéias Teatrais: o Século XIX no Brasil, embora tenha lido o estudo antes de sua publicação e, como diz o autor, contribuído com proveitosas sugestões. Mas se o tivesse feito, certamente exprimiria opinião semelhante, possivelmente com mais entusiasmo. Afinal, tratase do terceiro livro do autor, o de maior fôlego, um abrangente e profundo estudo sobre o teatro brasileiro no século XIX, realizado a partir de seis anos de exaustiva pesquisa em periódicos e revistas literárias da época, reunindo dezenas de artigos, críticas, ensaios, folhetins, cartas, prefácios e posfácios, num amplo levantamento dos fundamentos teóricos, controvérsias e polêmicas que cercaram a atividade teatral no período.

Dessa pesquisa saiu com um importante material crítico - algumas raridades cuja existência se desconhecia - de autores como Machado de Assis, Artur Azevedo, Quintino Bocaiúva, Fagundes Varela, Castro Alves, José de Alencar entre muitos outros nomes, conhecidos ou não, alguns deles poucas vezes associados à atividade teatral. E ainda com verdadeiros "achados", como dois manuscritos inéditos de peças de Aluísio Azevedo, nosso principal romancista do naturalismo; críticas de Machado de Assis jamais publicadas em livro, nem mesmo nas edições completas de sua obra publicadas pela Aguilar e pela Ajax e a recuperação na íntegra de uma importante - e deliciosa - polêmica entre o encenador francês André Antoine, precursor do naturalismo nos palcos europeus, e Artur Azevedo, o mais atuante dramaturgo brasileiro no fim do século XIX.

As primeiras 262 páginas do livro são dedicadas a traçar a progressão da atividade teatral no período, num trabalho de confronto, análise e síntese desses textos. A abrangência da pesquisa aliada à precisão na escolha das citações relevantes para a análise e ainda à forma como relaciona os textos entre si e às suas fontes inspiradoras européias resultam no redimensionamento da importância dessa arte no Brasil do século XIX. Nas demais páginas do volume, Faria publica uma antologia com os mais significativos textos pesquisados, colocando à disposição de futuros pesquisadores raridades que dormiam desconhecidas nas bibliotecas, para que "cada um possa discordar ou concordar saudavelmente dos meus pontos de vista", como diz no prefácio.

Como bom narrador, Faria prende a atenção do leitor - mesmo o não-especializado - com o enredo de sua história, dividida em quatro blocos: romantismo, realismo, teatro cômico e musicado e, por último, naturalismo. Uma história que se inicia com o vacilante nascimento do teatro brasileiro no período romântico, ainda preso a padrões clássicos e logo contaminado pelo melodrama, contaminação essa cujas consequiências podem ser sentidas até os dias atuais. Atinge incrível vitalidade em meados do século com a fundação do Ginásio Dramático, que traz para o palco o repertório realista de vanguarda na Europa e estimula um ardente debate na imprensa e o surgimento de uma dramaturgia nacional em moldes realistas, algo só comparável em importância com o surgimento do Teatro Brasileiro de Comédia, no século seguinte, e seus desdobramentos, a criação do Arena e do Oficina. Em seguida, vem a verdadeira tragédia do fenecimento desse surto criativo, com o divórcio do público que acorre em massa às operetas francesas que desembarcam no país. Acompanhamos então a ferrenha luta dos mais importantes intelectuais da época sugerindo e pedindo, através da imprensa, ações do poder públi- 
co que garantissem a continuidade do melhor teatro brasileiro.

Uma luta vã que não salvaria uma arte que conseguira a proeza de estar afinada pelo menos por uma década - com a vanguarda européia. A partir de 1865, tem início um infeliz retrocesso que moldará um quadro de decadência de nossa dramaturgia. Nesse quadro de crise, surgem as bem mais frágeis manifestações do naturalismo, mal compreendido entre nós, uma novidade em termos de historiografia, uma vez que o naturalismo sempre foi considerado inexistente no teatro brasileiro da época. O século termina com os palcos tomados pelo entretenimento, pelos espetáculos de aparato, feitos apenas para encher os olhos e pelas companhias estrangeiras. Nessa altura, o teatro brasileiro perde importância. Um retrocesso do qual só se recuperaria na metade do século seguinte, com o exílio involuntário no Brasil de diretores europeus fugidos da Segunda Guerra Mundial, quando essa arte retomaria no país a vitalidade alcançada em meados do século XIX.

Certamente há um grande mérito em contar uma história bem urdida, em linguagem fluente e de leitura prazerosa num estudo desse gênero. Mas sem dúvida a maior importância desse estudo está em representar um significativo avanço na história do teatro, ampliando consideravelmente o panorama explorado em historiografias anteriores sobre o século XIX. Como o título indica, Faria aborda a atividade teatral por um ângulo inédito - o pensamento crítico sobre essa arte - ao passo que estudos semelhantes tomaram como ponto de partida a dramaturgia. A primeira vantagem dessa opção é agregar à análise peças cujos originais se perderam. Só para antecipar um exemplo, o estudo traz à tona a repercussão na imprensa e até mesmo a reação do público da adaptação teatral feita por Aluísio Azevedo de seu romance $O$ Mulato. Até então se desconhecia essa adaptação, cujo original jamais foi encontrado. A abertura de visão propiciada por essa escolha aparece logo no início do volume. Se tomasse como ponto de partida a dramaturgia, iniciaria sua história em 1838 , data da estréia de Antonio José ou o Poeta da Inquisição, de Gonçalves Magalhães, acontecimento aceito como marco do nascimento do teatro brasileiro, no período romântico. Ou então, dois anos antes, quando o ator e empresário João Caetano inicia sua carreira profissional levando aos palcos do Teatro São Pedro um repertório europeu de tragédias clássicas, dramas românticos e melodramas. No entanto, ele inicia seu estudo com o texto "Ensaios sobre a Tragédia" publicado na $R e$ vista da Sociedade Filomática, em 1933, assinado por três jovens estudantes da Faculdade de Direito do Largo de São Francisco,
Quintino

Bocaiúva, em

desenho

publicado na

Revista

Ilustrada, de

dezembro de

1888

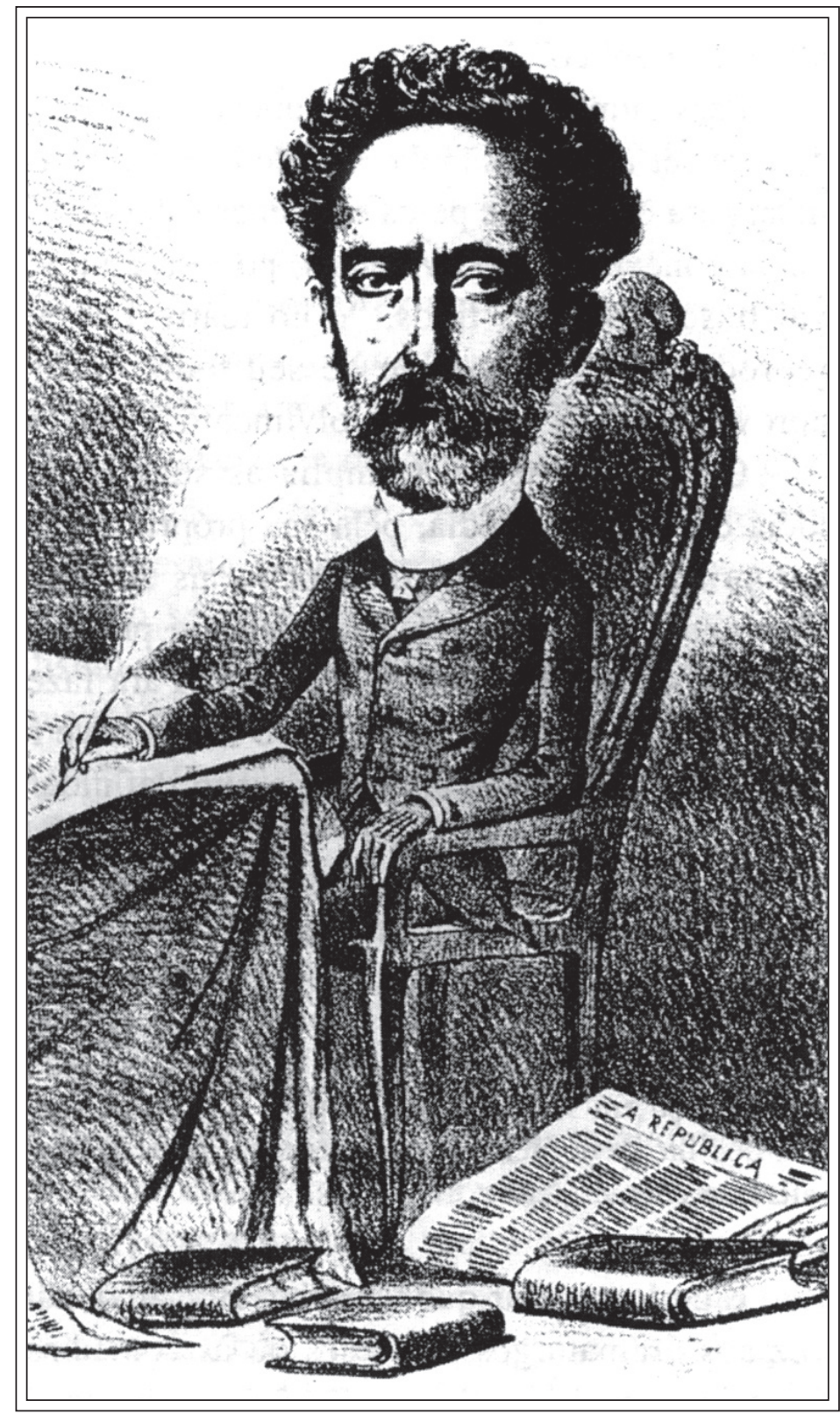


em São Paulo. Não é mera curiosidade. Com esse ensaio, publicado na íntegra na antologia final de Idéias Teatrais, os estudantes

\section{O dramaturgo}

Arthur Azevedo em ilustração do Boletim da SBAT tinham como objetivo incitaro aparecimento de uma dramaturgia nacional.

A forma como Faria comenta o ensaio é exemplar de seu método de análise em todo o volume. Nesse texto, os estudantes defendem com veemência as regras clássicas de construção de uma peça, o modelo

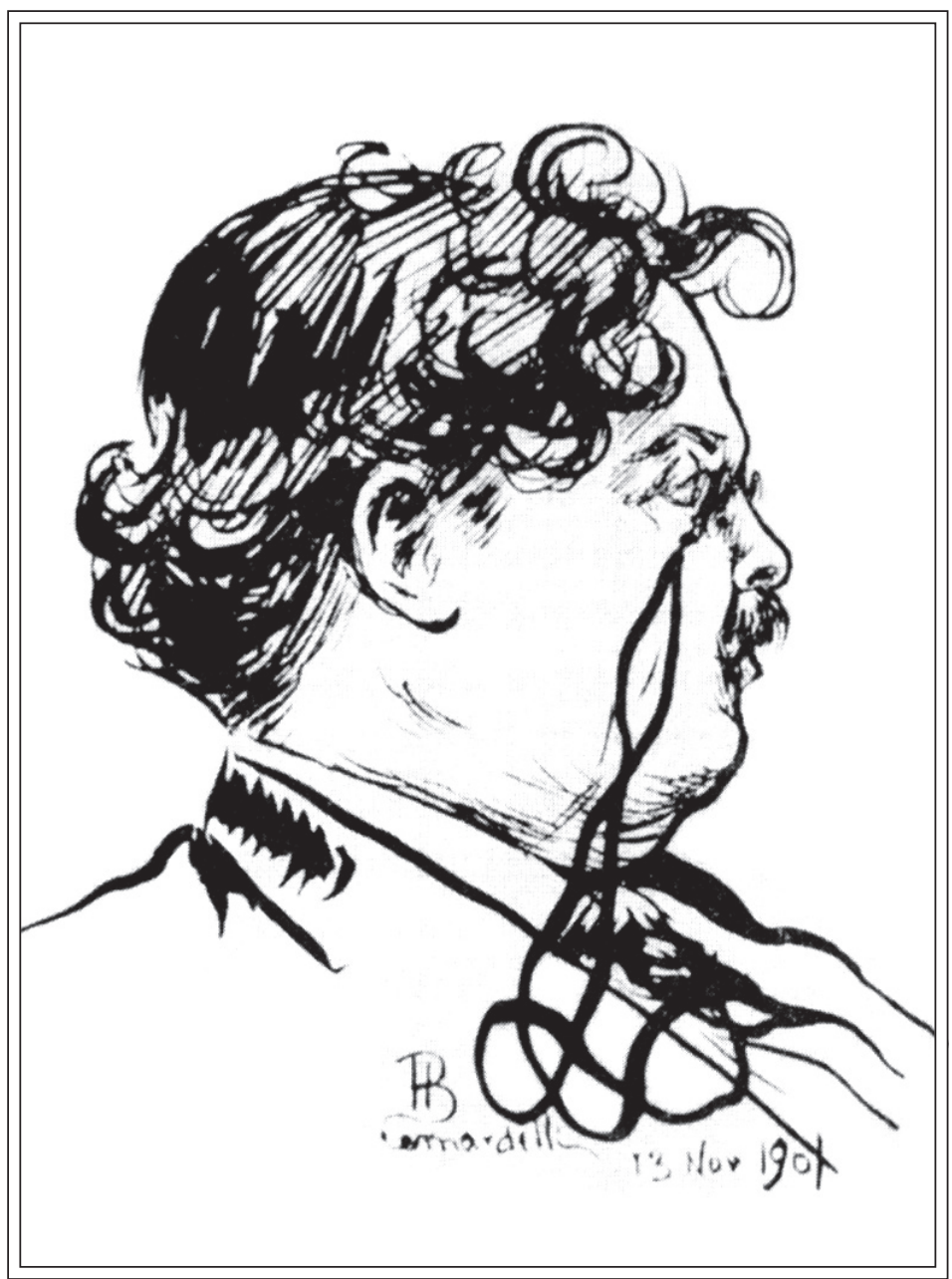

de Racine e Corneille - pelo qual, segundo eles, deveriam guiar-se os futuros dramaturgos brasileiros - contra o modelo de "gênios incultos" como Shakespeare e, principalmente, contra a "nova escola" que recebeu de Schiller o nome de romântica. Escrevem ainda que "essa sanha revolucionária também tem lavrado na França; Victor Hugo e Alexandre Domat são os corifeus da nova escola". Antes de mais nada, Faria chama a atenção para a grafia errada do nome de Alexandre Dumas, o que sugere o desconhecimento da dramaturgia romântica que a essa altura vinha obtendo enorme repercussão nos teatro de Paris. Não deixa de ser curiosa a adesão de estudantes europeizados aos padrões clássicos quando o romantismo já era vitorioso na Europa. Defasagem que não escapa à análise arguta de Faria, que destrincha as contradições do texto. E ainda revela a origem da formação clássica de Justiniano José da Rocha-ele estudou no Liceu Henrique IV, em Paris -, um dos autores do ensaio, destaque importante porque vamos encontrálo, três anos mais tarde, no papel de pioneiro da crítica teatral brasileira. Fundamental na consistência desse estudo é a forma como Faria "atravessa o oceano" para confrontar com as fontes européias as idéias que fundamentam as teorias de nossos intelectuais. Afinal, durante todo o século XIX o teatro europeu, principalmente o francês, servirá de modelo aos brasileiros.

Ao longo do estudo, acompanhamos a forma como as teorias que fundam cada estética vão sendo atualizadas e aclimatadas em nossos palcos, através do paralelo constantemente traçado entre a progressão do teatro brasileiro e sua absorção do modelo europeu. Um paralelo revelador de que os melhores momentos do teatro brasileiro no século XIX não foram os em que voltamos as costas para as novidades européias, mas aqueles em que a atualização foi intensa como no período realista em meados do século - quando então conseguimos mais traços de originalidade em relação ao modelo, tanto no que diz respeito ao pensamento crítico quanto à dramaturgia. Ao fim da leitura, fica a certeza de que, se o fluxo de criação que tem o seu auge no realismo não tivesse sido bruscamente interrompido pela avalanche de operetas, o teatro também estaria presente em 22, na Semana de Arte Moderna, apto a participar da festa "antropofágica".

Outra importante conseqüência do ângulo escolhido por Faria é agregar ao estudo o movimento do público, ponta essencial no processo de criação artística teatral. Ao contrário de uma pintura ou romance 
que pode ser criado no isolamento-e fruído até mesmo décadas depois - o teatro depende da presença do público no momento mesmo de sua criação. A escolha pela repercussão na imprensa traz à luz não só a reação do público a muitas das peças que subiram à cena, sua aceitação ou rejeição às novas estéticas, como ainda pinça os vários momentos em que esse público é apontado como "culpado" ora pela hegemonia do melodrama em nossos palcos, ora pela derrocada da dramaturgia brasileira no período pós-realista, seja por João Caetano no início do século ou Artur Azevedo, no final.

A importância da existência de um público afinado com o avanço da linguagem teatral é muito bem explicitada no capítulo dedicado ao realismo. Aliás, vale salientar que, se esse bloco não representa uma novidade em termos de historiografia como o dedicado ao naturalismo, cabe a Faria o crédito de ter iluminado esse período da nossa história teatral no seu livro anterior, O Teatro Realista no Brasil: 1855-1865, estudo que ele retoma nesse livro, abrindo mão de pormenores para ampliar as linhas gerais, o arcabouço. Ao iniciar o estudo dessa estética, ele vai buscar no panorama econômico as causas da existência de um público disposto à inovação no palco. A interrupção do tráfico negreiro deslocou o dinheiro até então investido na compra de escravos para a expansão das cidades. Surgem casas comerciais, bancos e pequenas indústrias e, em conseqüência, uma burguesia emergente. É nesse momento que aparece nos palcos europeus a comédia realista, cujo objetivo era o retrato dos "bons" costumes burgueses. Na definição de Alencar, essas comédias são "daguerreótipos morais", ou seja, "fotografias de costumes, retocadas com o pincel moralizante". No Brasil, o surgimento de um novo público burguês coincide com o momento em que a "vanguarda" no teatro era justamente o drama burguês. Um casamento perfeito.

Mas o autor mostra que outros fatores igualmente importantes contribuíram para o florescimento do teatro brasileiro nesse período. Depois de três decênios reinando absoluto, João Caetano já tinha sedimentado um teatro nacional. E é contra ele, e seu repertório anacrônico de melodramas "desconchavados", que começam a voltarse os jovens intelectuais, Machado de Assis e José de Alencar entre eles, que a essa altura começam a colaborar na imprensa. Jovens esses que apoiaram com muito entusiasmo, por meio de diversos artigos, críticas e folhetins, a abertura do Ginásio Dramático em 1855, “do ponto de vista do teatro brasileiro, o fato mais importante que aconteceu em meados do século XIX", escreve Faria na introdução do bloco relativo ao realismo.

A partir daí ele acompanha, através da imprensa, a atividade febril dos dez primeiros anos desse teatro, o decênio mais rico e produtivo do teatro brasileiro no século XIX. E traz à tona os avanços e recuos não só de nossa dramaturgia e produção crítica, mas também da cena, destacando, por exemplo, as polêmicas provocadas pelo ator que pela primeira vez deu as costas ao público ou pelo ensaiador que ousou ignorar a presença do público criando uma espécie de "quarta parede", antes de esse termo ser cunhado na Europa.

O ano de 1865, ano-limite escolhido por Faria, não marca o fechamento das portas do Ginásio Dramático, como a princípio pode parecer, porém, muito significativamente, um importante "movimento de público". Nesse ano estréia com estrondoso sucesso no Alcazar Lírico a ópera cômica Orphée aux Enfers, de Offenbach, ficando um ano em cartaz, numa época em que os maiores sucessos teatrais alcançavam duas dezenas de apresentações. Em breve surgiriam as paródias às operetas e, mais tarde, as revistas e os musicais brasileiros, que atrairiamo já escasso público daépoca. Essa avalanche não impediu que artistas ligados ao Ginásio continuassem levando aos palcos dramas e comédias realistas e, até mesmo, um pouco mais tarde, naturalistas. Mas passou a ser então uma atitude de resistência, com as necessárias concessões ao repertório fácil. E se já é difícil sustentar um teatro de qualidade em condições adversas, impossível ousar um repertório mais 
experimental. Sendo assim, voltados para a sobrevivência, nossos dramaturgos, atores e encenadores ignoraram os novos modelos europeus, que nasciam com Ibsen e Strindberg.

As implicações dessa dependência entre público e teatro e a certeza de que, em alguns momentos históricos, essa arte só avança livre da pressão da bilheteria, não escaparam aos intelectuais da época, como nos mostra Faria, que formaram uma comissão para elaborar um programa de apoio ao teatro brasileiro, Joaquim Manuel de Macedo e Machado de Assis entre eles. Num folhetim escrito em agosto de 1961 , Macedo já sugerira a criação de um Conservatório Dramático, mantido pelo governo, uma espécie de companhia/escola, nos moldes da Comédie Française. Recebendo salários fixos, os atores, depois de formados, trabalhariam durante alguns anos nessa companhia e depois seriam liberados. Faria nos diz que, segundo Macedo, "cabia ao governo criar um teatro que se pautasse apenas pelo interesse artístico, com um repertório que podia até afastar inicialmente o público já com o gosto corrompido. Isso não importava. Com o tempo, o próprio público seria educado pelas verdadeiras obras de arte que seriam representadas". Machado de Assis ia além e pedia censura para o repertório, de forma a impedir peças de má qualidade. "Será preciso dizer que as esperanças de Machado e dos intelectuais de seu tempo foram frustradas?", escreve Faria. A resposta é óbvia. E o leitor fica com a certeza de que seria outra a história do capítulo seguinte, o naturalismo, caso essas esperanças tivessem se concretizado, com o apoio do poder público.

Quando o naturalismo surge na Europa, nos palcos brasileiros o teatro cômico e musicado era hegemônico. Artur Azevedo, o comediógrafo que com mais talento "aclimatou" o gênero entre nós, era freqüentemente acusado de usar seu talento em prol de um teatro "menor". E respondia acusando "o público" que jamais prestigiou suas tentativas de fazer teatro "sério". Diante desse quadro, considerou-se inexistente a presença do naturalismo entre nós. Para se ter uma idéia, na mais recente historiografia teatral publicada pela Edusp, História Concisa do Teatro Brasileiro, de Decio de Almeida Prado, este afirma:

"Ao realismo, se a história tivesse lógica, seguir-se-ia o naturalismo, como aconteceu na França, e no que diz respeito ao romance histórico, também no Brasil, com Aluísio Azevedo sucedendo José de Alencar. Mas nos palcos do Rio de Janeiro, cidade que concentrava praticamente todo o teatro nacional, essa seqüência foi interrompida pela avalanche de música ligeira, que arrasou o pouco que o romantismo e o realismo haviam conseguido construir sobre a designação de drama”.

Portanto, a grande novidade do volume reside em trazer à tona a existência do naturalismo em nossos palcos. Idéias Teatrais contém 60 páginas inteiramente dedicadas à repercussão dessa estética entre nós.

Igualmente importante é o fato de agregar à antologia final dez textos críticos sobre o naturalismo, de autores como Araripe Junior, Olavo Bilac e Paulo Barreto, o João do Rio, entre outros. Dos dois manuscritos de peças inéditas de Aluísio Azevedo encontrados por Faria, Venenos que Curam e OCaboclo, a segunda foi escrita em moldes naturalistas e assim comentada nos jornais da época. E Aluísio Azevedo adaptou para a cena seu romance $O$ Mulato, adaptação cujo original se perdeu, mas gerou comentários na imprensa, analisados por Faria.

Nesse bloco, mais uma vez, o autor inicia sua análise pelas fontes européias, reproduzindo partes das polêmicas publicadas nos jornais franceses em torno das adaptações dos romances de Émile Zola aos palcos franceses, que pouco depois chegariam aos palcos brasileiros. E mostra-nos que a recepção ao naturalismo foi difícil também na França. "Identificar o naturalismo como um estética voltada para a escabrosidade, a patologia, o mórbido, o pessimismo e a imoralidade era uma atitude comum tanto na imprensa francesa quanto na brasileira", escreve Faria ao comen- 
tar uma das críticas da encenação de $O$ Mulato, que estreou no Teatro Recreio Dramático, no dia 17 de outubro de 1884. Mas ressalta ainda que essa incompreensão não foi unânime. Silvio Romero foi um dos articulistas que parecem ter compreendido perfeitamente o "traço novo" dessa dramaturgia, não mais preocupada, como a anterior, com o "papel moralizador junto à sociedade".

Num desrespeito inteligente à rigidez cronológica, Faria finaliza o estudo com a polêmica entre Artur Azevedo e o encenador Antoine, iniciada na passagem do encenador francês pelo Brasil, em 1903. A polêmica tem início no Brasil, numa conferência de Antoine no Teatro Lírico, onde apresentava seu repertório. O pivô da discórdiaé um temido e respeitado crítico francês, Francisque Sarcey, que havia morrido em 28 de maio de 1899 e não aceitara as inovações da estética naturalista. Citado nominalmente por Antoine em sua palestra como o "Sarcey" brasileiro - alguém maldosamente teria traduzido para Antoine justamente os trechos negativos das críticas de Azevedo ao seu trabalho - o comediógrafo e crítico dá o troco através da imprensa. A polêmica que inicia no campo das idéias degenera em agressões quando os jornais brasileiros publicam cartas de Antoine, já na Europa, com citações do tipo “destruí esse homem no espírito de seus compatriotas". A polêmica está publicada na íntegra na antologia. Um fecho para o volume que não deixa de ser simbólico. Afinal, um século que vê o teatro brasileiro nascer na década de 30 , a princípio defasado com relação ao seu modelo europeu para alcançar, vinte anos depois, incrível atualização, termina num "bate- boca" entre o expoente de nossa dramaturgia e um dos mais importantes encenadores da vanguarda européia. Um divórcio que durará muito tempo.

A antologia publicada no volume reforça a análise feita por Faria. Em linhas gerais, os textos relativos ao romantismo são fruto de iniciativas isoladas, com idéias ainda muito coladas ao modelo europeu, ao passo que a produção crítica do realismo revela um conteúdo programático - quase sempre em oposição à estética romântica defendida por João Caetano - e, além disso, dialogam entre si e com o que ocorre nos palcos brasileiros. Sempre associados à decadência do teatro brasileiro, os gêneros cômicos e musicados geraram poucas análises sobre espetáculos e mais textos que apontam sua interferência na "deformação" do gosto do público e na derrocada da dramaturgia brasileira. Os textos sobre o naturalismo revelam a dificuldade da aceitação desse gênero entre nós.

Com esse livro Faria presta uma grande contribuição ao teatro brasileiro. Pelo afinco e perseverança na pesquisa, pela agudeza de análise, pela arte de conseguir uma escrita simples sobre o que é complexo e pela consistência e amplitude de conhecimentos, prova ser o herdeiro intelectual de Decio de Almeida Prado, de quem foi aluno e a quem substituiu - a convite do mestre - no cargo de professor de Literatura da Universidade de São Paulo (USP). E sua contribuição não deve encerrar-se nesse volume. Faria já começou a pesquisa para um futuro livro sobre o teatro brasileiro, no período que vai desde o início do século XX até 1943, data da estréia de Vestido de Noiva, de Nélson Rodrigues, marco que inaugura o modernismo nos palcos tropicais. 